\title{
A note on corporate taxation, limited liability, and asymmetric information*
}

\author{
Anton Miglo ${ }^{\dagger}$
}

April 2007

\begin{abstract}
Becker and Fuest (forthcoming) provides a new explanation for the important and puzzling link between limited liability and corporate taxation. The authors argue that a corporate tax on all entrepreneurs with limited liability is optimal when entrepreneurs can offset potential losses and when asymmetric information exists regarding projects' qualities. This note considers a model with slightly modified production technology. It confirms that entrepreneurs' abilities to offset losses and the existence of asymmetric information may affect government policy. However, it also shows that the optimal taxation policy differs from that in Becker and Fuest (forthcoming).
\end{abstract}

*I thank the Editor, Giacomo Corneo, two anonymous referees, James Amegashie, Henry Thille, and the seminar participants at the University of Guelph for useful suggestions and comments.

${ }^{\dagger}$ University of Guelph, Department of Economics, Guelph, Ontario, Canada, N1G 2W1, tel. (519) 824-4120, ext.53054, email: amiglo@uoguelph.ca 


\section{Introduction.}

Becker and Fuest (forthcoming) analyzes the link between corporate taxes and limited liability rights of corporations. Traditional "folk" opinion is that corporate tax is the price corporations pay for the right of limited liability. However, there is no formal proof of this argument. Musgrave and Musgrave (1980) and Rosen (2004) noticed that it is hard to believe in the link between the real amount of benefits corporations receive from limited liability and the magnitude of corporate taxation.

Becker and Fuest (forthcoming) turns to asymmetric information to address the issue. The authors present a simple model and proceed step by step to achieve their goal. They consider an environment where entrepreneurs choose between risky projects, with high potential profitability, and safe projects, with minimal profitability. An entrepreneur's incentive depends on the financing contracts. There are two contracts available: one with limited liability and one with unlimited liability. The entrepreneurs choose contracts based on a trade-off between interest rates (unlimited liability contracts have a lower interest rate) and a loss in the bad state (limited liability contracts do not imply a loss for the entrepreneur in the bad state). Becker and Fuest argue that the equilibrium is inefficient: some entrepreneurs use limited liability contracts and invest inefficiently (overinvestment problem). Corporate taxation reduces the incentive to overinvest and leads to an efficient equilibrium.

This note shows that in a model with slightly modified production technology (in the spirit of Stiglitz and Weiss (1981), Gale (1990), Hillier and Ibrahimo (1992), and Bracoud and Hillier (2000)) both types of inefficiencies can arise (overinvestment and underinvestment) and optimal government policy includes corporate taxes for some entrepreneurs and subsidies for others (Sections 2 and 3).

\section{The model.}

Consider a set of entrepreneurs, indexed by $j$, with investment projects available. Projects require the same amount of external financing equal to 1 . In the case of success a project generates a cash flow $F_{j}$ and a cash flow of zero otherwise. The probability of success is $p_{j}$. There is also a risk-free investment project with cash flow $I<F_{j}-1$. The income tax rate is $t$. There are 
two types of financing available for the risky project. One is a limited liability contract (LLC). Here, an entrepreneur borrows an amount 1 from a bank. In the case of success, the entrepreneur pays $D$ to the bank. If the project fails the parties have no returns. Alternatively, the entrepreneur can use an unlimited liability contract (ULC). It is assumed that each entrepreneur has sufficient collateral, equal to 1 . Hence, ULC represents a risk-free debt for the bank and thus has a face value of $1 .^{1}$ An entrepreneur can offset losses if the project fails (one can think, for instance, about alternative sources of revenue which are subject to income taxation - in the case where the project fails, these taxes can be reduced). The degree to which the losses can be offset depends on $\alpha_{i}, i \in\{1,2\}$, where $i$ denotes the entrepreneur's type. If the project fails, the entrepreneur loses $1-\alpha_{i} t$. If $\alpha_{i}=0$, the entrepreneur loses 1. A higher $\alpha_{i}$ means a smaller loss. Entrepreneurs belonging to class 1 have $\alpha_{1}=1$ and entrepreneurs from class 2 have $\alpha_{2}<1$. This means that the entrepreneurs from class 1 have better opportunities to offset losses. $F_{j}$, $p_{j}$ and $i$ are the private information of each entrepreneur. Banks do not have this information. Entrepreneurs and banks are risk-neutral. The model is the same as in Becker and Fuest (forthcoming) except that the entrepreneurs differ in $F_{j}{ }^{2}$

\section{Underinvestment and overinvestment.}

The following equation separates socially efficient risky projects from socially inefficient projects:

$$
p_{j} F_{j}-1=I
$$

If the left side is greater, the project is socially efficient and vice versa. For marginal entrepreneurs (marginal entrepreneurs' projects satisfy (1)) $\partial p_{j} / \partial F_{j}=-(1+I) / F_{j}^{2}<0$ and $\partial^{2} p_{j} / \partial F_{j}^{2}=2(1+I) / F_{j}^{3}>0$.

We have the following set of equations which determine an equilibrium. The choice between the LLC and the risk-free project is given by:

$$
p_{j}\left(F_{j}-D\right)=I
$$

\footnotetext{
${ }^{1}$ Equity is ruled out. Thus, the results of Becker and Fuest (forthcoming) can be better applied to firms which do not have access to equity markets or firms with a high agency cost of equity.

${ }^{2}$ Stiglitz and Weiss (1981), Gale (1990), Hillier and Ibrahimo (1992), and Bracoud and Hillier (2000).
} 
where $D=1 / p^{*}$ and $p^{*}$ is the average probability of success among the entrepreneurs with a LLC. For this equation we also have $\partial p_{j} / \partial F_{j}<0$ and $\partial^{2} p_{j} / \partial F_{j}^{2}>0$. If an entrepreneur's project satisfies (2) he is indifferent between the LLC and the risk-free project. If the left side is greater, the entrepreneur chooses the LLC and vice versa.

The choice between the LLC and the ULC is given by:

$$
p_{j}\left(F_{j}-1 / p^{*}\right)(1-t)=p_{j}\left(F_{j}-1\right)(1-t)-\left(1-p_{j}\right)\left(1-\alpha_{i} t\right)
$$

which can be rewritten as:

$$
p_{j}=\frac{1-\alpha_{i} t}{t-\alpha_{i} t+(1-t) / p^{*}}
$$

and the choice between the ULC and the risk-free project is given by:

$$
p_{j}\left(F_{j}-1\right)(1-t)-\left(1-p_{j}\right)\left(1-\alpha_{i} t\right)=I(1-t)
$$

The analysis of equations (1)-(4) reveals the following. (a) From (1) and (2) the marginal entrepreneur with $p_{j}=p^{*}$ is indifferent between the LLC and the risk-free project. (b) From (1) and (3) marginal entrepreneurs with $p_{j}=p^{*}$ and perfect loss offset are indifferent between the LLC and the ULC because the right side of $(3)$ is equal to $p^{*}$ when $\alpha_{i}=1$. Marginal entrepreneurs with $p_{j}=p^{*}$ and imperfect loss offset prefers the LLC to the ULC. This is because the right side of (3) is greater than $p^{*}$ since $\alpha_{2}<1$. (c) Marginal entrepreneurs with perfect loss offset are indifferent between the ULC and the risk-free project. Marginal entrepreneurs with imperfect loss offset prefer the risk-free project to the ULC. To see this let us rewrite (1) and (4) as follows:

$$
\begin{gathered}
p_{j}=(1+I) / F_{j} \\
p_{j}=\left[I(1-t)+1-\alpha_{i} t\right] /\left[\left(F_{j}-1\right)(1-t)+1-\alpha_{i} t\right]
\end{gathered}
$$

For class 1 entrepreneurs $\left(\alpha_{i}=1\right)$ the right side of (6) equals that of (5) and for class 2 entrepreneurs it is greater than that of (5) because $F_{j}>1+I$ and $0 \leq \alpha_{2}<1$.

Figures $1 \mathrm{a}$ and $1 \mathrm{~b}$ illustrate the equilibrium decision-making for the entrepreneurs of class 2 and 1 respectively. The thick lines represent equations (1)-(4). Letters $f, l$ and $u$ denote the areas where the entrepreneurs choose the risk-free contract, the limited liability contract, or the unlimited liability contract respectively. 


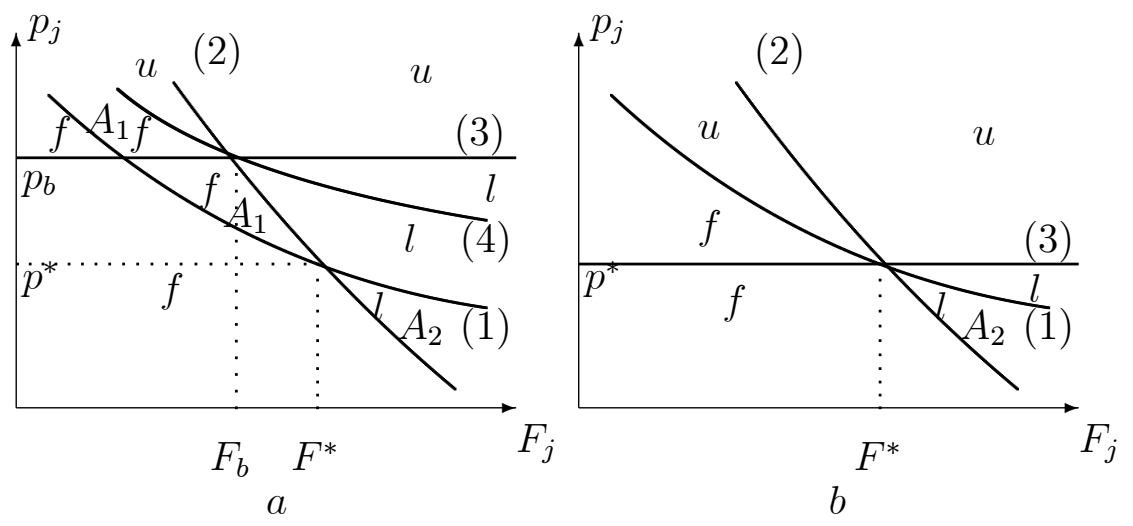

Figure 1. Overinvestment and underinvestment.

Consider Figure 1a (type 2 entrepreneurs). From the remark (a) above the point of intersection of (1) and (2) has the probability of success $p_{j}=p^{*}$. The intersection is unique since the slope of (1) is greater than that of (2): $-\frac{1+I}{F_{j}^{2}}=-\frac{p^{2}}{1+I}>-\frac{I}{\left(F_{j}-D\right)^{2}}=-\frac{p^{2}}{I}$. From (b) the line corresponding to (3) lies above the line $p_{j}=p^{*}$. From (c) the line corresponding to (4) lies above the line corresponding to (1). Finally, the lines corresponding to (2) and (6) cross $(3)$ at the same point $\left(F_{b}, p_{b}\right)$ where

$$
F_{b}=1 / p^{*}+\left[I t\left(1-\alpha_{2}\right)+I / p^{*}(1-t)\right] /\left[1-\alpha_{2} t\right]
$$

Now consider Figure $1 \mathrm{~b}$ (class 1 entrepreneurs). Since $\alpha_{1}=1$, eq. (1) and (4) are identical. The right side of (3) equals $p^{*}$.

As follows from Figure 1, there are two areas of inefficiency. Firms in area $A_{1}$ underinvest (only class 2) and firms in area $A_{2}$ overinvest (and use the LLC). What explains these results?

First, consider entrepreneurs with unlimited liability. Class 1 entrepreneurs can perfectly offset losses under the unlimited liability contract. This means that the after-tax return (in the case of either success or failure) equals the before-tax earnings/loss multiplied by $(1-t)$. Also, the unlimited liability contract is a risk-free debt for the bank. Thus, the entrepreneur's before-tax expected earnings equal the project's expected earnings $\left(p_{j} F_{j}\right)$ reduced by the payment to the bank (which equals the investment cost 1 ). This means that under unlimited liability, class 1 entrepreneurs will not invest in socially inefficient projects because they are always better-off with the risk-free investment (eq. (1)). The same holds for class 2 entrepreneurs because they 
earn less than class 1 entrepreneurs given imperfect loss offset (line (4) lies above the line (1)).

Secondly, consider entrepreneurs with limited liability. From (1) marginal entrepreneurs have projects with equal expected values. In area $A_{2}$ marginal entrepreneurs have lower probabilities of success than $p^{*}$ (the average probability of success among entrepreneurs with limited liability contracts). A higher probability of default is detrimental for creditors. Thus, marginal entrepreneurs in area $A_{2}$ make a positive surplus compared to the symmetric information case. This implies that there are some entrepreneurs with a lower probability of success than marginal entrepreneurs which will choose limited liability investment in risky projects (similar to the asset substitution effect). ${ }^{3}$ On the other hand, marginal entrepreneurs in area $A_{1}$ have a higher probability of success which is beneficial for creditors and harmful for shareholders because they receive a lower return in the good state. Thus, some entrepreneurs with a high probability of success will not invest in socially efficient risky projects. Optimal government policy will include a tax on entrepreneurs with limited liability contracts and high earnings (high $F_{j}$ ) and subsidies for entrepreneurs with limited or unlimited liability contracts and low earnings (low $F_{j}$ ). ${ }^{4}$ This will move line $(2)$ toward line (1) reducing areas $A_{1}$ and $A_{2} \cdot{ }^{5} \mathrm{~A}$ universal tax on all entrepreneurs with limited liability is never optimal because it will move line (2) up and to the right, increasing area $A_{1}$.

The result of Becker and Fuest (forthcoming) emerges as a particular case when $F_{j}$ are equal among the entrepreneurs. Figure 2 illustrates their result. ${ }^{6}$

\footnotetext{
${ }^{3}$ DeMeza and Webb (1987).

${ }^{4}$ Mathematical calculations of the optimal tax rate and the amount of subsidies are omitted for brevity. Note that they depend on whether the government is able to observe (ex-post) the type of entrepreneur or only the amount of earnings.

${ }^{5}$ Also note that in Becker and Fuest (forthcoming) all entrepreneurs have sufficient collateral (that makes debt risk-free for banks). It can be shown that if this assumption is relaxed one can have an equilibrium where some entrepreneurs with unlimited liability overinvest. Thus, optimal policy may include taxes on some entrepreneurs with unlimited liability.

${ }^{6}$ Note that the analysis above holds regardless the distribution of entrepreneurs' types in the economy. For example, the density of some types can be equal zero.
} 

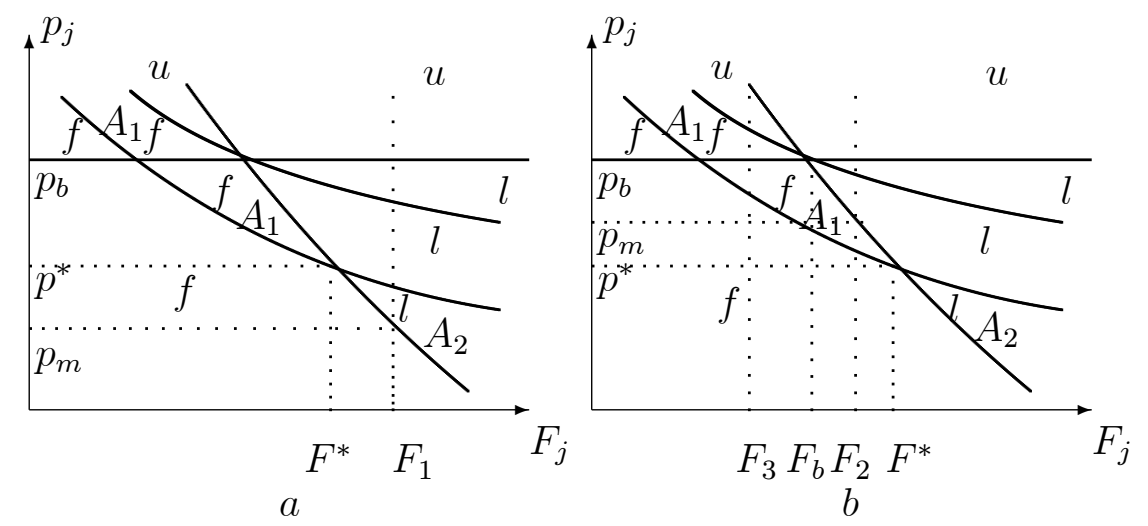

Figure 2. The case of Becker and Fuest (forthcoming).

The only possible equilibrium when the market for LLCs does not collapse is when $F_{j}=F_{1}>F^{*}$ (Figure 2a). In such a situation there exists an entrepreneur, with a probability of success $p_{m}<p^{*}$, who is indifferent between the LLC and the risk-free project. From (2), the entrepreneur's profit is increasing in $p_{j}$ under limited liability. Thus, entrepreneurs with $p_{j}$ such that $p_{m}<p_{j}<p_{b}$ choose the LLC (as was shown above $p_{b} \geq p^{*}$ ). This case corresponds to Proposition 1 in Becker and Fuest (forthcoming). The only possible inefficiency in their paper is overinvestment (area $A_{2}$ ). Now suppose that an equilibrium exists where $F_{j}<F^{*}$ (Figure 2b). Consider the case $F_{j}=F_{2}>F_{b}$. Then $p_{m}>p^{*}$ and the entrepreneurs with $p_{j}$ such that $p_{b}>p_{j}>p_{m}$ undertake the project with the LLC. But this implies $p_{m}<p^{*}$ (since $p^{*}$ is the average probability of succes among the entrepreneurs with the LLC) leading to a contradiction. Finally, consider the case $F_{j}=F_{3}<F_{b}$. As one can see from Figure 2 the market for LLCs collapsed here. In equilibrium entrepreneurs choose either the ULC or the risk-free project. $1 / p^{*}$ can be interpreted as the face value of off-equilibrium LLC offered by banks (which is too high for entrepreneurs). ${ }^{7}$

The above analysis was based on slight modificastions of the production technology in Becker to Fuest (forthcoming). Some additional insights can be obtained with regard to the model's implicit assumptions regarding the government. For example, if the government can determine entrepreneurs' classes then an alternative policy exists. Consider the eq. (4). Suppose the

\footnotetext{
${ }^{7}$ The last situation is not considered in Becker and Fuest (forthcoming). Here the only inefficiency is the underinvestment problem. Therefore, the optimal policy would be subsidizing some entrepreneurs with unlimited liability.
} 
government subsidizes class 2 entrepreneurs if they have an unlimited liability contract and the bad state is realized. If the amount of subsidization equals $t-\alpha_{2} t$ (the difference between perfect loss offset and imperfect loss offset), the decision-making would be optimal, as is easy to see from (4). The entrepreneur's net payoff in the bad state would be $(t-1)$ and the condition (4) converts to (1). Thus, the entrepreneurs' decision-making will be optimal ex-ante. The use of unlimited liability insures the first-best outcome in the model. There is no need for limited liability contracts. In Figure 1a the effect of such a subsidy will be to move (4) toward (1) and (3) toward $p_{j}=p^{*}$. While the government cannot observe the quality of the projects, it can distinguish class 1 entrepreneurs from class 2 entrepreneurs by observing (possibly ex-post) their income from other sources. If the government cannot observe entrepreneurs' incomes from other sources, and thus cannot distinguish between class 1 and 2, the first-best outcome is never achievable through subsiding entrepreneurs with unlimited liabilily alone. This is because any subsidy will bias class 1 entrepreneurs towards overinvestment with unlimited liability financing. In these conditions, optimal government policy may contain other instruments. ${ }^{8}$

To summarize, we believe that the idea in Becker and Fuest (forthcoming) about the impact of different loss offset opportunities under asymmetric information is interesting and must certainly be taken into consideration by government tax authorities. However, in our opinion, the implications of this idea are only partly explored by Becker and Fuest (forthcoming).

\section{References}

Becker, J., and C. Fuest, (forthcoming), Why is there corporate taxation? The role of limited liability revisited, Journal of Economics.

Bracoud, F., and B. Hillier, 2000, Equity or debt? Contracts in markets with asymmetric information, Manchester School 68, 1-23.

\footnotetext{
${ }^{8}$ Note that Becker and Fuest implicitly assume that the government cannot change personal tax rates. Otherwise the model has a trivial solution similar to that described above: the government will set $t=0$ and the condition (4) becomes: $p_{j} F_{j}-1=I$. Unlimited liability contracts constitute a first-best pooling equilibrium where all types invest efficiently. One can argue that a personal tax rate exists because there is a public good. However, it does not explain why the personal tax rate is fixed and cannot be changed. For instance, the government can finance this public good by levying a lumpsum tax on all entrepreneurs.
} 
DeMeza, D., and D. Webb, 1987, Two much investment: a problem of asymmetric information, Quarterly Journal of Economics 102, 281-92.

Gale, W., 1990, Federal credit and the market for lending, Journal of Public Economics 42, 177-193.

Hillier, B., and M. Ibrahimo, 1992, The performance of credit markets under asymmetric information about project means and variances, Journal of Economic Studies 19, 3-17.

Musgrave, R., and P. Musgrave, 1980, Public finance in theory and practice, McGraw-Tokyo.

Rosen, H. Public Finance. McGraw-Hill/Irwin; 7 edition, 2004.

Stiglitz, J., and A. Weiss, 1981, Credit rationing in markets with imperfect information, American Economic Review 71, 393-410. 